\title{
Management of severe haemophilia A during surgery: case report
}

Ma Hazel Cordial

We describe the case of a patient with severe haemophilia $A$ and significant comorbidities who underwent surgery to remove a large intra-abdominal haematoma first diagnosed 12 years previously. The haemophilia team was instrumental in coordinating care, building a strong rapport with surgical and other medical teams to manage bleeding risk with continuous infusion of factor VIII (FVIII). Medical teams adjusted their working hours according to clinical need. Haemophilia nurses were available to offer support at all times, and developed management procedures and educated staff on haemophilia and its treatment. Perioperative complications included a thrombus occluding the right internal jugular vein, infection and paraesthesia. However, surgery was effective and the patient was pleased with the overall outcome. Haemophilia nurses established strong and rewarding relationships with other teams that will enhance the delivery of care in the future.

Keywords: haematoma, haemophilia, nurses, surgery

\section{here is a lack of evidence-based guidance on the prevention of bleeding during surgery in people with haemophilia due to the difficulties of carrying out appropriate} trials in this setting and the scarcity of published

MA HAZEL CORDIAL

Haemophilia Nurse Specialist, Hampshire Hospital

NHS Foundation Trust, Basingstoke, UK.

Email: MaHazel.Cordial@hhft.nhs.uk

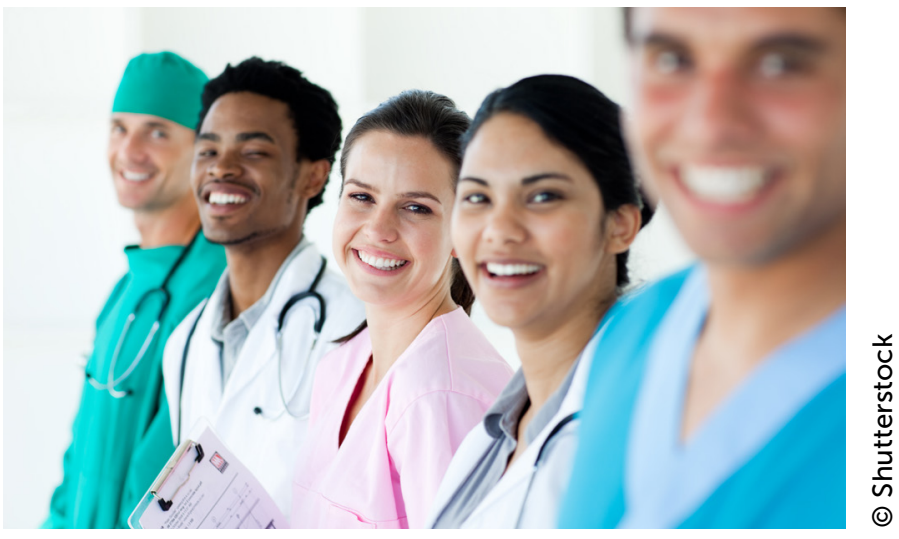

Haemophilia specialist nurses play a vital role in planning and coordinating care for people with haemophilia undergoing surgery. The surgical team, the wider multidisciplinary team and patients all gain significantly from their involvement in ensuring the safe and effective delivery of care.

reports ${ }^{[1,2]}$. Clinical experience has been embodied in local protocols for the administration of replacement clotting factor and monitoring trough levels and bleeding ${ }^{[3]}$. Here, we present a case study of a patient with severe haemophilia A with significant comorbidities, who underwent surgery to remove a large haematoma in which bleeding risk was managed with human coagulation FVIII (Fanhdi; Grifols).

\section{THE PATIENT}

The patient is a 62-year-old Caucasian patient with severe haemophilia A and several comorbidities that affect his surgical management (Table 1 ). He is married and has two children; he takes the younger child to and from school. He is retired, does not smoke and says he drinks 24 units of alcohol per week.

The patient's baseline Factor VIII is $<1 \mathrm{IU} / \mathrm{dL}$, and his Factor VIII inhibitor screens have always been

This is an Open Access article distributed under the terms of the Creative Commons Attribution-NonCommercial-NoDerivs License (https://creativecommons.org/licenses/by-nc-nd/3.0/) which permits use and distribution in any medium, provided the original work is properly cited, the use is non-commercial, and no modifications or adaptations are made. Copyright is retained by the authors. 
Table 1. Comorbidities and current treatment

\begin{tabular}{l|l|l} 
DIAGNOSIS & MEDICATION & DOSE \\
\hline HIV & $\begin{array}{l}\text { Tenofovir/emtricitabine } \\
\text { Raltegravir } \\
\text { tenofovir/emtricitabine }\end{array}$ & 400 mg twice daily \\
\hline Chronic hepatitis B co-infection & FVIII & 40 IU/kg (3000 IU) on alternate days, \\
\hline increased to daily administration, March 2017
\end{tabular}

negative. His haemophilia is managed by prophylaxis with plasma-derived factor VIII concentrate (Fanhdi) at a dose of $40 \mathrm{lU} / \mathrm{kg}$ three times weekly. His management has always been challenging due to his comorbidities, and is further complicated by low adherence to his prophylaxis regime and non-compliance with online Haemtrack treatment recording. He has a generalised haemophilia-related arthropathy. His surgical history includes surgical repair of intussusception at age 18 months, left knee replacement and left ankle fusion.

The patient was co-infected with HIV, and Hepatitis B and $C$. Hepatitis $C$ was cleared with antiviral therapy and hepatitis $B$ is currently inactive. Pericarditis was diagnosed in November 2016; this resolved and he was discharged from cardiology follow-up in February 2017. He also has hypertension (controlled by ramipril) and epilepsy.

\section{EPILEPSY}

In 2005, the patient was diagnosed with small cavernomas and since then has had bilateral minor cerebral bleeds, resulting in epilepsy. Seizures affect the frontal and parietal lobes and are controlled with phenytoin. In 2012, an MRI scan revealed multiple haemosederin-lined cavernomas. His last neurological episode was in August 2016, when he presented with a four-week history of intermittent headaches and dizziness. There was no evidence of papilloedema or abnormal neurological signs. A CT scan revealed multiple areas of possible punctate bleeding, the largest area measuring $15 \mathrm{~mm}$ in the left parietal lobe. A second MRI scan confirmed multiple cavernomas. After neurosurgical and neuroradiological review, it was concluded that there was no clear evidence of new bleeds and therefore no need for surgical intervention. The patient was, however, prescribed tranexamic acid to reduce the risk of re-bleeding. He has been seizurefree for the past seven years while taking phenytoin.

\section{ILIOPSOAS MUSCLE HAEMATOMA}

In 2005, a right lliopsoas muscle haematoma was identified as a chance finding during an abdominal ultrasound scan. The appearance was consistent with a chronic haematoma with no apparent active bleeding and no indication for surgery; FVIII replacement was continued.

In May 2009, after referral to the pseudomyxoma team in Basingstoke Hospital for surgical consideration, an initial CT angiogram revealed haematoma in the right psoas muscle measuring $10.2 \times 11.8 \times 14.3 \mathrm{~cm}$. There was medial deviation of the psoas border and extension into the ileo-psoas tendon. The team felt that it was unlikely that any surgical intervention to remove the haematoma would be possible.

The iliopsoas muscle haematoma was monitored and managed conservatively by the patient's local haemophilia centre. In 2010, the haematoma was shown to have increased in length to $13.5 \mathrm{~cm}$, with a diameter of $10.5-11.3 \mathrm{~cm}$. At this stage, the patient was not experiencing any symptoms related to his rightsided abdominal pseudo tumour.

When the patient was admitted to hospital in the latter part of 2016 with chest pains, shortness of breath and dry cough associated with an acute episode of pericarditis, an abdominal scan was performed to rule out PE and aortic dissection. This was negative, but it showed that the iliopsoas haematoma had increased in size to $18 \times 26 \times 17 \mathrm{~cm}$, displacing the right iliac vessel and inferior vena cava to the left and right kidney superiorly. There was some soft tissue swelling medial to the haematoma of uncertain aetiology. Enlarged iliac chain and groin lymph nodes were noted, although there was no obvious superficial lymphadenopathy clinically. The liver and spleen were normal. Clinical opinion was that the chest pains and other symptoms were possibly secondary to compression of the diaphragm by the 


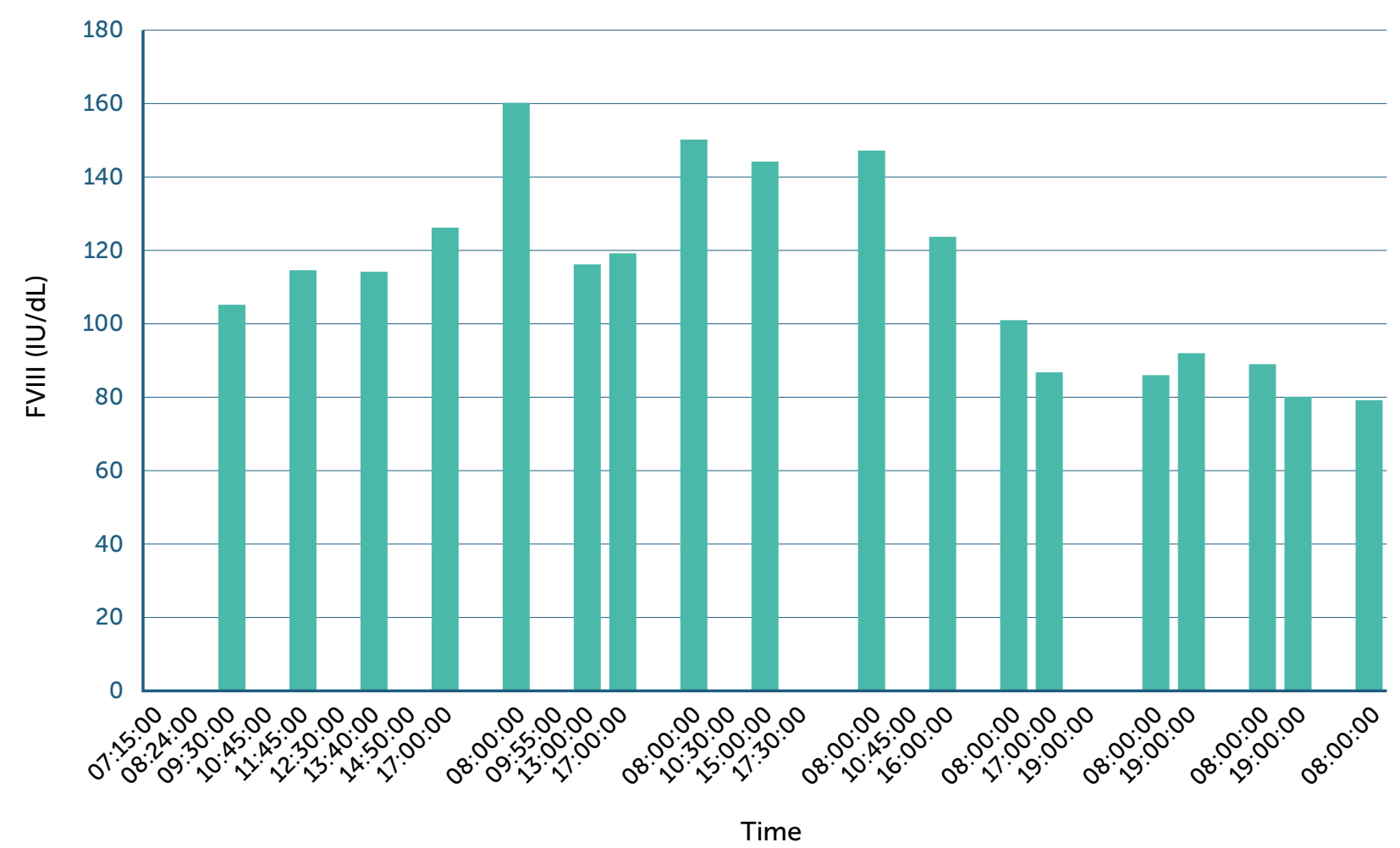

Figure 1. FVIII levels during continuous infusion

enlarged haematoma. At this time it was decided to increase the frequency of FVIII prophylaxis to daily.

The enlargement of the right psoas haematoma was now becoming symptomatic and the patient was re-referred to the pseudomyxoma team at Basingstoke Hospital. A repeat CT angiogram confirmed that the haematoma had increased in size to $17 \times 14.5 \times 24 \mathrm{~cm}$. After discussing the options available, the patient decided to undergo excision of the organised haematoma.

\section{PRE-SURGERY PREPARATION}

Prior to surgery, care was taken to ensure that members of the haemophilia care team liaised with other members of the multidisciplinary team (MDT) on how to approach the patient's treatment before, during and after surgery.

The MDT agreed the best course of treatment post-surgery would be continuous infusion of FVIII, with a target level of $100 \%$ for at least the first two weeks, which would then be re-evaluated depending on his clinical progress. A continuous infusion clotting factor chart was developed that met local guidelines on intravenous infusion. Staff on intensive treatment and high dependency units and surgical ward staff were provided with education and training about haemophilia A and factor replacement therapy. The principles of continuous factor infusion and factor preparation were explained and demonstrated using dummy kits supplied by the product manufacturer. This included the preparation of the continuous infusion syringe.

Emphasis was placed on the importance of monitoring FVIII levels, adherence to specified testing times, the correct handling of coagulation tubes and prompt delivery of samples to the specified coagulation laboratory personnel.

The haemophilia team supported the surgical team by providing an assured open line of communication at all times. Specific attention was given to working with the surgical team and the anaesthetists to avoid veins the patient used to administer his factor prophylaxis so that he could resume self-treatment at home as soon as possible. The haemophilia care team also liaised with the anaesthetist to ensure the FVIII level was sufficient before the epidural was removed post-surgery, stressing the need to minimise discard of factor to avoid undue costs.

\section{SURGERY}

The patient underwent excision of an organised right flank haematoma and appendicectomy in May 2017. His weight was $75 \mathrm{~kg}$. A bolus dose of FVIII $53 \mathrm{IU} / \mathrm{kg}$ (4000 IU) was administered preoperatively, followed one hour later by continuous infusion of FVIII at a dose of $5 \mathrm{lU} / \mathrm{kg} / \mathrm{hr}$. The total operating time was four hours 
and 20 mins. The estimated blood loss was $1.4 \mathrm{~L}$; the patient received fluid replacement with Crystalloid $3 \mathrm{~L}$ and Gelaspan $500 \mathrm{ml}$. His FVIII level dropped by 50 IU/ $\mathrm{dL}$ after one hour of surgery; therefore, an additional bolus of $13 \mathrm{IU} / \mathrm{kg}$ (1000 IU) was administered and the continuous infusion rate was increased to $6 \mathrm{lU} / \mathrm{kg} /$ hour. He subsequently received two further boluses of FVIII 13 IU/kg (1000 IU) approximately three and five hours later. The continuous infusion rate was increased from $5 \mathrm{lU} / \mathrm{kg}$ to a maximum of $7 \mathrm{lU} / \mathrm{kg}$ in the first seven hours, and was then gradually decreased to 2 $\mathrm{IU} / \mathrm{kg}$ on day three, and $3 \mathrm{IU} / \mathrm{kg}$ on days four and five. Continuous infusion of FVIII continued up to postsurgical day seven (see Table 2). Figure 1 shows the FVIII activity levels with continuous infusion over the first seven days post-surgery. The patient was switched to twice daily bolus infusion until his discharge on day 18 (9 June 2017) when, due to weight loss to $72 \mathrm{~kg}$, this was reduced to once daily administration of $41.6 \mathrm{IU} / \mathrm{kg}$ (3000 IU). Dose frequency reduced to alternate days on postoperative day 28 .

On the second day after surgery, the patient developed paraesthesia in his hands and fingers, possibly due to ulnar nerve compression from the arm extension position while in theatre. Symptoms resolved on the right by day three but persisted in the left hand until he was discharged.

Postoperative recovery was otherwise uneventful until day 10 , when the patient developed neck swelling and odynophagia a day after the central venous catheter (CVC) was removed. An ultrasound scan revealed a clot occluding the right internal jugular vein. Further investigation with Doppler ultrasound scan demonstrated no thrombus in either leg. Anticoagulation with enoxaparin sodium began at a dose of $60 \mathrm{mg}$ twice daily. That evening, Staphylococcus aureus was identified in the abdominal drain and intravenous flucloxacillin $1 \mathrm{~g}$ four times daily was prescribed. His FVIII levels on this day were 70.4 IU/ dl trough and $102.5 \mathrm{lU} / \mathrm{dL}$ post-dose.

By day 13 the neck swelling was reduced and the patient found swallowing easier; flucloxacillin was switched to oral administration. FVIII levels were $57 \mathrm{lU} / \mathrm{dL}$ trough and $87 \mathrm{lU} / \mathrm{dL}$ post-dose. On day 14 , a repeat ultrasound scan showed continued complete occlusion of the right internal jugular vein, but the patient was now mobile. On day 16 , discharge planning discussions were initiated with the patient and his wife, including planned teaching of enoxaparin injections and FVIII administration. He was discharged on day 18 with a commitment to liaise with the haemophilia team. The dose of enoxaparin was reduced to $80 \mathrm{mg}$ once daily, to be injected two to three hours before FVIII and continued for two weeks, at which time a repeat neck ultrasound scan was planned.

\section{THREE-MONTH FOLLOW-UP}

On follow-up by telephone after three months, the patient reported that he was doing well, although he was still experiencing paraesthesia in his left arm and hand, and mentioned in particular numbness of the left ring and little fingers.

Enoxaparin was stopped as scheduled and FVIII infusions were switched back to prophylaxis. Although the patient reported experiencing no symptoms, repeat neck ultrasound scan revealed no change in the thrombus. His appetite was returning and his general health seemed to be recovering slowly.

The patient was happy with the overall outcome of surgery and was referred to the haematology department for ongoing management of the thrombus in consultation with the multidisciplinary team.

\section{DISCUSSION}

The planning, preparation, and open and prompt communications between the surgical and medical teams achieved a good outcome in this complex case. The constant and continued availability of the haemophilia team paved the way for good working relationships, which clearly benefited patient care.

Prior to this particular case, the local hospital trust did not have suitable guidelines, infusion charts and plans for managing a patient with haemophilia during and after surgery. These were prepared from scratch, based on the continuous infusion guideline used by the Katharine Dormandy Haemophilia and Thrombosis Centre at the Royal Free Hospital, London (to whom special thanks are due). In collaboration with staff on the intensive treatment and high dependency units, the haemophilia care team were able to create the Hampshire Hospital NHS Foundation Trust Clotting Factor Continuous Infusion Sheet.

Effective liaison and pre-operative planning resulted in the Special Coagulation Team rearranging their work shifts in order to provide test results as rapidly as possible. This doubtless contributed to target FVIII activity levels being achieved throughout the duration of the patient's hospital stay. The development of a thrombus completely occluding the jugular vein post-CVC removal and a microbiology report of an infection was challenging. However, 
factor replacement therapy was continued with daily review, continuous monitoring of the FVIII activity level and treatment with enoxaparin.

Considerable effort is required to develop and coordinate complex care plans to manage factor replacement in patients with haemophilia when they undergo surgery. Both the surgical team and the patient gain significantly from the involvement of haemophilia nurses, especially when they develop a strong rapport with the wider care team.

The role of haemophilia nurses in developing documentation, providing education and ensuring that the practical aspects of therapy were well managed increased the confidence and knowledge of all staff, enabling the safe and effective delivery of care and supporting adherence to the treatment protocol.

\section{ACKNOWLEDGEMENTS}

The authors have advised no interests that might be perceived as posing a conflict or bias.
Informed consent has been obtained from the individual reported in this case study.

\section{REFERENCES}

1. Coppola A, Windyga J, Tufano A, et al. Treatment for preventing bleeding in people with haemophilia or other congenital bleeding disorders undergoing surgery. Cochrane Database Syst Rev 2015; 2: CD009961. doi: 10.1002/14651858. CD009961.pub2.

2. Neufeld EJ, Solimeno L, Quon D, et al. Perioperative management of haemophilia B: a critical appraisal of the evidence and current practices. Haemophilia 2017; 23: 821-31.

3. Hampshire Hospital NHS Foundation Trust. Haemophilia treatment plan for abdominal surgery. Clinical guidelines: haemophilia and other bleeding disorders. 23 May 2017; ratified 12 March 2018.

HOW TO CITE THIS ARTICLE:

Cordial MH. Management of severe haemophilia A during surgery: case report. J Haem Pract 2019; 6(1): 1-6. https:// doi.org/10.17225/jhp00131.

Table 2. Postoperative management

\begin{tabular}{|c|c|c|c|c|c|c|}
\hline $\begin{array}{l}\text { POSTOPERATIVE } \\
\text { DAY }\end{array}$ & TIME & $\begin{array}{l}\text { FVIII BOLUS } \\
\text { DOSES (IU) }\end{array}$ & $\begin{array}{l}\text { FVIII CONTINUOUS } \\
\text { INFUSION RATE } \\
\text { (ML/HR) }\end{array}$ & $\begin{array}{l}\text { DOSAGE } \\
\text { (IU/KG) }\end{array}$ & $\begin{array}{l}\text { FVIII LEVEL } \\
\text { (IU/DL) }\end{array}$ & CLINICAL ACTIVITY \\
\hline \multirow[t]{9}{*}{ Day 0} & 07:15 & 4000 & & & $\begin{array}{l}\text { Pre }-43.1 \\
\text { Post }-152.6\end{array}$ & \\
\hline & $08: 24$ & & 3.75 & 5 & & CVP insertion, epidural, catheter, NGT \\
\hline & 09:30 & & & & 105 & \\
\hline & $10: 45$ & 1000 & 4.5 & 6 & & \\
\hline & $11: 45$ & & & & 114.4 & \\
\hline & $12: 30$ & 1000 & & & & \\
\hline & $13: 40$ & & & & 114 & $\begin{array}{l}\text { End of theatre }-3 \text { abdominal drains } \\
\text { (silicone drain, Abdovac and Redivac) }\end{array}$ \\
\hline & $14: 50$ & & 5.25 & 7 & & Transfer to intensive care unit \\
\hline & $17: 00$ & & & & 126 & \\
\hline \multirow[t]{4}{*}{ Day 1} & 08:00 & & & & 160 & Extubated \\
\hline & 09:55 & & 4.5 & 6 & & \\
\hline & $13: 00$ & & & & 116 & \\
\hline & 17:00 & & & & 119 & TPN infusion started \\
\hline \multirow[t]{4}{*}{ Day 2} & 08:00 & & & & 150 & \\
\hline & $10: 30$ & & 3 & 4 & & Clear fluids only \\
\hline & $15: 00$ & & & & 144 & \\
\hline & $17: 30$ & & 2.25 & 3 & & \\
\hline \multirow[t]{3}{*}{ Day 3} & 08:00 & & & & 147 & \\
\hline & $10: 45$ & & 1.5 & 2 & & NGT out \\
\hline & $16: 00$ & & & & 123.5 & \\
\hline \multirow[t]{3}{*}{ Day 4} & 08:00 & & & & 100.8 & Epidural out \\
\hline & $17: 00$ & & & & 86.6 & \\
\hline & 19:00 & & 2.25 & 3 & & \\
\hline Day 5 & 08:00 & & & 3 & 85.8 & \\
\hline
\end{tabular}




\begin{tabular}{|c|c|c|c|c|c|c|}
\hline $\begin{array}{l}\text { POSTOPERATIVE } \\
\text { DAY }\end{array}$ & TIME & $\begin{array}{l}\text { FVIII BOLUS } \\
\text { DOSES (IU) }\end{array}$ & $\begin{array}{l}\text { FVIII CONTINUOUS } \\
\text { INFUSION RATE } \\
\text { (ML/HR) }\end{array}$ & $\begin{array}{l}\text { DOSAGE } \\
\text { (IU/KG) }\end{array}$ & $\begin{array}{l}\text { FVIII LEVEL } \\
\text { (IU/DL) }\end{array}$ & CLINICAL ACTIVITY \\
\hline & 19:00 & & & & 91.8 & \\
\hline \multirow[t]{2}{*}{ Day 6} & 08:00 & & & & 88.8 & \\
\hline & 19:00 & & & & 79.9 & \\
\hline \multirow[t]{3}{*}{ Day 7} & $08: 00$ & & & & 79 & \\
\hline & 09:00 & & Stop FVIII & & & \\
\hline & $17: 00$ & 3000 & & & $\begin{array}{l}\text { Pre }-78.7 \\
\text { Post }-133.2\end{array}$ & \\
\hline \multirow[t]{2}{*}{ Day 8} & $08: 30$ & 2000 & & & $\begin{array}{l}\text { Pre }-65.4 \\
\text { Post }-107.4\end{array}$ & \\
\hline & $20: 30$ & 1500 & & & & \\
\hline \multirow[t]{2}{*}{ Day 9} & 09:00 & 1500 & & & $\begin{array}{l}\text { Pre }-68 \\
\text { Post }-100.5\end{array}$ & \\
\hline & 2100 & 1500 & & & & \\
\hline \multirow[t]{2}{*}{ Day 10} & 09:00 & 1500 & & & $\begin{array}{l}\text { Pre }-70.4 \\
\text { Post }-102.5\end{array}$ & $\begin{array}{l}\text { Neck swelling - right side / pain } \\
\text { when swallowing. USS revealed clot } \\
\text { occluding right internal jugular vein. } \\
\text { No collection. } \\
\text { Enoxaparin } 60 \text { mg twice daily } \\
\text { (administer } 2 \text { hours before FVIII) } \\
\text { Bilateral leg Doppler USS - normal }\end{array}$ \\
\hline & 21:00 & 1500 & & & & $\begin{array}{l}\text { Staph aureus growth at Abdovac } \\
\text { drain - start Flucloxacillin } 1 \mathrm{~g} \text { four } \\
\text { times daily }\end{array}$ \\
\hline \multirow[t]{2}{*}{ Day 11} & 09:00 & 1500 & & & & \\
\hline & 21:00 & 1500 & & & & \\
\hline \multirow[t]{2}{*}{ Day 12} & 09:00 & 1500 & & & & \\
\hline & 21:00 & 1500 & & & & \\
\hline \multirow[t]{2}{*}{ Day 13} & 09:00 & 1500 & & & $\begin{array}{l}\text { Pre }-57 \\
\text { Post }-87\end{array}$ & $\begin{array}{l}\text { Swelling reduced; swallowing easier. } \\
\text { Continue Clexane. }\end{array}$ \\
\hline & $21: 00$ & 1500 & & & & \\
\hline \multirow[t]{2}{*}{ Day 14} & 09:00 & 1500 & & & & $\begin{array}{l}\text { Repeat neck USS - right internal } \\
\text { jugular vein remains completely } \\
\text { occluded with thrombus }\end{array}$ \\
\hline & 21:00 & 1500 & & & & \\
\hline \multirow[t]{2}{*}{ Day 15} & 09:00 & 1500 & & & & \\
\hline & $21: 00$ & 1500 & & & & \\
\hline \multirow[t]{2}{*}{ Day 16} & 09:00 & 1500 & & & $\begin{array}{l}109.3 \text { (45 mins } \\
\text { post-FVIII) }\end{array}$ & \\
\hline & $21: 00$ & 1500 & & & & \\
\hline \multirow[t]{2}{*}{ Day 18} & & 3000 daily & Discharge home & & & $\begin{array}{l}\text { Clexane to continue at smaller dose: } \\
80 \mathrm{mg} \text { OD for } 2 \text { weeks.( to be injected } \\
2-3 \text { hours before FVIII) } \\
\text { Repeat neck USS in Bournemouth 2/52 }\end{array}$ \\
\hline & & 3000 alt days & & & & Stop Clexane \\
\hline Total FVIII used & & 99,500 & & & & $\begin{array}{l}\text { From admission to discharge } \\
\text { (day } 1 \text { to } 18 \text { ) }\end{array}$ \\
\hline
\end{tabular}

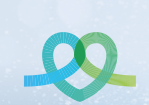

The Journal of Haemophilia Practice

\section{An open-access journal for sharing experience in the care of people with bleeding disorders}

